\title{
Study and clinical evaluation of 25 cases of primary amenorrhea
}

\author{
Jaydeep J. Bhatu*, Govind B. Bhadaraka
}

Department of Obstetrics and Gynecology, GMERS Medical College and Hospital, Sola, Ahmedabad, Gujarat, India

Received: 23 November 2019

Revised: 25 December 2019

Accepted: 31 December 2019

\section{*Correspondence:}

Dr. Jaydeep J. Bhatu,

E-mail: bhatujaydeep@gmail.com

Copyright: () the author(s), publisher and licensee Medip Academy. This is an open-access article distributed under the terms of the Creative Commons Attribution Non-Commercial License, which permits unrestricted non-commercial use, distribution, and reproduction in any medium, provided the original work is properly cited.

\section{ABSTRACT}

Background: Primary amenorrhea is absence of menstruation and secondary sexual characters by age of 14 years primary amenorrhea is < 1\%. Development of female genital organs takes place from mullerian DUCT (paramesonephric duct). The objective of this study was to note the various causes, complete clinical picture and the management in 25 such cases of primary amenorrhea.

Methods: This is a prospective study done in 25 cases. They were investigated, managed and patients were called up for follow up for their response to treatment.

Results: Out of 25 cases studied, maximum cases presented at 14-16 years of age, with chief complaint of primary amenorrhea, out of which $8 \%$ were married, $44 \%$ cases were of MRKH syndrome which was the most common cause of primary amenorrhea.

Conclusions: Amenorrhea has got multi factorial etiology. For patients with amenorrhea physical examination should focus on pubertal development and possible genital out flow obstruction.

Keywords: Cryptomennorhea, Mayer-Rokitansky-Küster-Hauser syndrome, Mullerian duct, Primary amenorrhea, Turner syndrome

\section{INTRODUCTION}

Primary amenorrhea is absence of menstruation and secondary sexual characters by age of 14 years or absence of menstruation regardless of secondary sexual characters by age of 16 years. Menstruation, also known as a 'period' or 'monthly', is a regular discharge of blood and tissue from the inner lining of the uterus through vagina. ${ }^{1}$ For a normal menstruation to occur the genetic makeup, neuroendocrinological, embryological development is must. Any abnormality in above leads to amenorrhea. Menstruation marks the transition from a girl to a woman. It is the physical manifestation noticed of all pubertal changes and last to occur. ${ }^{1}$ Incidence of primary amenorrhea is $<1 \%$. Development of female genital organs takes place from Mullerian duct (paramesonephric duct). Sexual development starts after 8 weeks. In absence of $\mathrm{Y}$ chromosome, functional testes and lack of
AMH, mullerian duct develops and form uterus, fallopian tubes and upper vagina and at the same time in absence of testosterone, Wolffian duct regresses. ${ }^{2}$ Ovaries are formed from coelomic epithelium. Hymen is formed by invagination of posterial wall of urogenital sinus and usually ruptures spontaneously in perinatal period. Menarche is the end of cascade of events occurring in puberty. $^{3}$

\section{Causes of primary amenorrhea can be}

Classified according to WHO as: ${ }^{4}$

1. Hypogonadotropic hypogonadism (Group 1)

[Decreased estrogen, normal or low FSH, and no lesion in hypothalamic-pituitary region]. 
- Physiologic delay

- Kallman syndrome

- CNS tumors.

2. Hypergonadotropic hypogonadism (Group 2)

[decreased estrogen, but raised $\mathrm{FSH}]^{4}$

3. Development defect of genital tract (Group 3)

The objective of this study is to evaluate the age of presentation, presenting symptom, clinical findings of general and local examination, causes, outcome and management of 25 cases of primary amenorrhea presented in department of obstetrics and gynecology, Sola Civil Hospital Ahmadabad.

\section{METHODS}

This is a prospective study. Observation analysis with inferential statistics method, study period from January 2017 to January 2018. Study area - Sola Civil Hospital all patient with primary amennorhea with following inclusion criteria.

\section{Inclusion criteria}

- Unmarried girl with anomalous pathology of genital track like MRKH syndrome, imperforate hymen, cervical agenesis with vaginal septum, turner syndrome, androgen insensitivity syndrome, pure gonadal agenesis.

\section{Exclusion criteria}

- Married women with infertility

- Other infective etiology for genital tract.

A methodical, systemic approach was developed to achieve best diagnosis. Evaluation of primary Amenorrhea is designed to separate the reproductive system into its distinct structural components such as genital outflow track, uterus, ovaries, pituitary, hypothalamus and to test functional integrity of each beginning at lowest level and progressing systemically to higher levels until the cause is determined. 25 case of primary amenorrhea were studied in detail for following parameters-

- Age of presentation

- Presenting complaint (associated with cyclical pain)

- Marital status

- Past history of any medical illness

- Family history

- General built (height, weight, BMI and arm span)

- Presence of secondary sexual characters (according to tanner's staging)

- Local examination

- Hormonal profile (FSH, LH, Estrogen, AMH, TSH)
- $\quad$ Radiological investigations (USG, MRI)

- Karyotyping.

\section{RESULTS}

As Table 1 shows that in present study presenting age was from 11 to 25 years in which most age group was from 14-16-year age following that 11-13 year, as authors seen after 21 year it was only $20 \%$.

Table 1: Presenting age was in range from 11 to 25 years.

\begin{tabular}{|ll|}
\hline Age & Percentage \\
\hline $11-13$ years & $6(24 \%)$ \\
\hline $14-16$ years & $9(36 \%)$ \\
\hline $17-19$ years & $4(16 \%)$ \\
\hline $19-21$ years & $3(12 \%)$ \\
\hline$>$ than 21 years & $3(12 \%)$ \\
\hline
\end{tabular}

Table 2: Presenting symptoms in primary amenorrhea.

\begin{tabular}{|ll|}
\hline Symptom & Percentage \\
\hline Primary amenorrhea & $13(52 \%)$ \\
\hline Cyclical abdominal pain & $5(20 \%)$ \\
\hline Ambiguous genitalia & $3(12 \%)$ \\
\hline Urinary retention & $4(16 \%)$ \\
\hline
\end{tabular}

Table 2 shows that, out of 25 cases, 5 had complaint of cyclical pain associated with primary amenorrhea. Out of 25 cases, 3 of the patients were married and 22 were unmarried.

Table 3: Causes of primary amenorrhea in present study.

\begin{tabular}{|ll|}
\hline Causes & Percentage \\
\hline MRKH syndrome & $11(44 \%)$ \\
\hline Imperforate hymen & $5(20 \%)$ \\
\hline Cervical agenesis with vaginal septum & $3(12 \%)$ \\
\hline Turner syndrome & $2(8 \%)$ \\
\hline Androgen insensitivity syndrome & $2(8 \%)$ \\
\hline Pure gonadal agenesis & $2(8 \%)$ \\
\hline
\end{tabular}

As Table 3 shows that MRKH syndrome is the most common cause of primary amennorhea in our study i.e. $44 \%$. These patients had normal secondary sexual characters that was symmetric with age. They had normal development of breasts which indicates normal ovarian function.

\section{DISCUSSION}

MRKH syndrome is the most common cause of primary amennorhea in our study i.e., 44\%. These patients had normal secondary sexual characters that were symmetric with age. They had normal development of breasts which 
indicates normal ovarian function. ${ }^{5}$ All had normal karyotyping (46XX). MRI is gold standard to diagnose any congenital anomalies. ${ }^{2}$ These patients were explained about their pathology and counseled regarding their menstrual and reproductive function. Primary goal of management in MRKH syndrome is creation of functional vagina. They were explained about vaignaplasty and were called for follow-up before 6 months of their marriage. MRKH syndrome is associated with renal, cardiac and skeletal malformations. ${ }^{6}$ Thus all the cases of MRKH syndrome underwent USG KUB, 2D echo and X-ray spine. $16 \%$ of them were associated with renal malformations.

There were 5 cases of cryptomennorhea, 4 presented with complaint of cyclical lower abdominal pain and 1 case with urinary retention. All of them had normal symmetrical secondary sexual characters and normal breast development indicating normal ovarian function. All the cases were managed surgically and 1 case with recurrent hematometra and hematocolpos, total hysterectomy was done, ovaries were preserved.

Patient with turner syndrome presented with c/o primary amenorrhea with short stature, shield chest (widely spaced nipples) with underdeveloped breast and absent pubic and axillary hairs (Tanner stage I). MRI pelvis suggested of $6 \times 4 \mathrm{~mm}$ of hypoplastic uterus with absent ovaries. Karyotyping s/o mosaicism 45, x, (92)/46, x, I (x) (910), $92 \%$ of cell with XO and $8 \%$ of cells with $\mathrm{XX}{ }^{7,8}$ She was given withdrawal with oral contraceptive pills (MALA-N) and since then patient is menstruating normally. ${ }^{2}$ DECHO and USG KUB was normal.

\section{CONCLUSION}

Amenorrhea has got multi factorial etiology. For patients with amenorrhea physical examination should focus on pubertal development and possible genital outflow obstruction. Mullerian agenesis (MRKH syndrome) was the most common cause of primary amenorrhea. Early surgery offered to patients may reduce patients suffering, help restore patients outflow tract and may preserve fertility in some cases. Research on mullerian anomalies is limited and further studies are needed. Out of 25 cases of primary amenorrhea, $44 \%$ had MRKH syndrome, $20 \%$ had imperforate hymen, $12 \%$ had cervical agenesis with transverse vaginal septum, $8 \%$ had turner syndrome, $8 \%$ had disorder sex development and $8 \%$ had pure gonadal agenesis.

\section{Funding: No funding sources \\ Conflict of interest: None declared}

Ethical approval: The study was approved by the Institutional Ethics Committee

\section{REFERENCES}

1. Rock JA, Jones HW. TeLinde' s Operative Gynaecology. $10^{\text {th }}$ ed. New Delhi: Lipincott Williams and Wilkins; 2009:550-590.

2. Troiano RN. Magnetic resonance imaging of mullerian duct anomalies of the uterus. Topics Magn Reson Imag. 2003;14(4):269-79.

3. Griffin JE, Edwards C, Madden JD, Harrod MJ, Wilson JD. Congenital absence of the vagina: the Mayer-Rokitansky-Kuster-Hauser syndrome. Ann Int Med. 1976;85(2):224-36.

4. Folch M, Pigem I, Konje JC. Müllerian agenesis: etiology, diagnosis, and management. Obstet Gynecol Surv. 2000;55(10):644-9.

5. Varner RE, Younger JB, Blackwell RE. Müllerian dysgenesis. The J Reprod Med. 1985;30(6):443-50.

6. Strubbe EH. Mayer-Rokitansky-Kuster-Hauser syndrome: distinction between two forms based on excretory urographic, sonographic, and laparoscopic findings. Am J Roentgenol. 1993;160:331-4.

7. Golden NH, Carlson JL. The pathophysiology of amenorrhea in the adolescent. Ann New York Academy Sci. 2008;1135(1):163-78.

8. Speroff L, Fritz MA, editors. Clinical gynecologic endocrinology and infertility. Lippincott Williams and Wilkins; 2005.

Cite this article as: Bhatu JJ, Bhadaraka GB. Study and clinical evaluation of 25 cases of primary amenorrhea. Int J Reprod Contracept Obstet Gynecol 2020;9:666-8. 